\title{
Gratitude to God, Self-Rated Health, and Depressive Symptoms
}

\author{
NeAL KRAUSE \\ Department of Health Behavior and Health Education \\ University of Michigan
}

DEBORAH BRUCE

Research Services

Presbyterian Church

\author{
R. DAVID HAYWARD \\ University of Michigan \\ CYNTHIA WOOLEVER \\ Research Services \\ Presbyterian Church
}

Department of Health Behavior and Health Education

\begin{abstract}
This study has three goals. The first is to see whether the opportunity to engage in volunteer work at church fosters friendships with co-religionists. The second goal is to see whether the support these friends provide bolsters feelings of gratitude to God. The third goal is to see whether feelings of gratitude to God are associated with health and depressive symptoms. The following linkages in our conceptual model elaborate and extend these objectives: (1) people who go to church more often will be more likely to participate in volunteer work through their congregations; (2) individuals who perform volunteer work at church will have more friends among their co-religionists; (3) people who have more friends where they worship will report receiving more emotional support from fellow congregants; (4) those who receive more support from co-religionists will feel more grateful to God; and (5) individuals who are more grateful to God will rate their health in a more favorable manner and experience fewer symptoms of depression. Data from the U.S. Congregational Life Survey provide support for each of these relationships.
\end{abstract}

Keywords: gratitude to God, health, depressive symptoms.

\section{INTRODUCTION}

Feelings of gratitude are an essential social lubricant that helps bolster and maintain sound interpersonal relationships in a number of ways (Algoe, Haidt, and Gable 2008). For example, research indicates that expressing gratitude helps ensure that a support provider will continue to provide assistance in the future (Tsang 2007). Carlisle and Tsang (2013:424) define gratitude as "a positive emotional reaction to the receipt of a benefit that is perceived to have resulted from the good intentions of another." Research on gratitude is important because a number of studies suggest that people who are grateful experience fewer symptoms of depression (Wood, Froh, and Geraghty 2010), an increased positive affect (Froh et al. 2009), and fewer symptoms of physical illness (Emmons and McCullough 2003). Although these findings are encouraging, two major gaps remain in the literature.

First, the wide majority of studies focus on global or general feelings of gratitude while fewer studies assess feelings of gratitude to God specifically. Based on the definition provided by Carlisle and Tsang (2013), we define gratitude to God as a positive emotional reaction to the receipt of a benefit that is perceived to have resulted from the good intentions of God. Second, although research is beginning to show that feeling more grateful to God is associated with

Note: This research was supported by grants from the John Templeton Foundation and the Lilly Endowment.

Correspondence should be addressed to Neal Krause, Department of Health Behavior and Health Education, School of Public Health, University of Michigan, 1415 Washington Heights, Ann Arbor, MI 48109-2029 USA. E-mail: nkrause@umich.edu 
better physical (Krause 2006a) and better psychological well-being (Rosmarin et al. 2011), less is known about how feelings of gratitude to God arise in the first place.

Researchers rarely discuss the ways in which gratitude to God may differ from feeling grateful to other people. The differences between the two types of gratitude may arise from the way in which many people view God. Barna reports results of four nationwide surveys suggesting that between 71 and 72 percent of the study participants believe that "God is the all-powerful, all-knowing, perfect creator of the universe who rules the world today" (2006:14). The vast differential in power between God and the average human being points to at least three ways in which gratitude to God may differ from feeling grateful to other people.

First, as Harpham (2004:25) points out, expressing gratitude to another human being is relatively straightforward, but it is less clear how feelings of gratitude to God are best expressed. For example, should gratitude be expressed through prayers of thanksgiving or does doing good works for people who are in need represent the best way to show gratitude to God?

Second, as Komter (2004) maintains, the expression of gratitude is likely to be complicated by issues of power and dependence, but her discussion focuses entirely on expressions of gratitude to other people. As a result, the ways in which power differentials affect gratitude to God raises a number of questions that have yet to be answered. Because God is often viewed as the ultimate ruler of the universe, does He even need or want human expressions of gratitude? And if He does, does God reward those who are grateful and punish people who are not grateful?

Third, as Krause (2006a) maintains, if God is the all-powerful and all-knowing ruler of the world, then God is in a far better position than human beings to provide help during stressful times. So if the benefits that God can provide when stressors arise are substantially greater than the benefits that humans can provide, then perhaps feelings of gratitude to God are significantly greater when difficult times are encountered.

As research reviewed by Galen (2012) suggests, religious beliefs, such as feelings of gratitude to God may be confounded with other widely used measures in the literature, such as life satisfaction and subjective well-being. One way to address the issue of confounding involves finding an instance in which feelings of gratitude to God may not necessarily reflect a greater sense of well-being. The point we raise above that involves whether God rewards the grateful and punishes those who are not grateful is one such instance. As a recent qualitative study by Krause et al. (2012) reveals, some people believe God punishes those who are not grateful and as a result, the gratitude they express is driven by negative social sanctions. If a person feels pressured to express gratitude to God then it seems that he or she may not experience the same sense of well-being as does a person who expresses gratitude to God for sincere and heartfelt reasons. So if feelings of gratitude to God may enhance well-being in some instances but fail to do so under other conditions, then it follows that gratitude to God and well-being may not reflect the same underlying construct.

The purpose of this study is to examine the relationship between feelings of gratitude to God, self-rated health, and depressive symptoms. We evaluate the relationships among these constructs with data from the U.S. Congregational Life Survey.

In the process of evaluating the relationship between gratitude to God, health, and well-being, we develop and evaluate a conceptual model that assesses a potentially important factor that may influence whether people feel grateful to God in the first place-social relationships in the church. There are three reasons why church-based social ties may be especially important in this respect. First, for over 100 years, researchers in a number of disciplines have argued that religion arises from and is sustained by social relationships that arise in places of worship (e.g., Baldwin 1902). Second, Hood, Hill, and Spilka (2009) maintain that one of the primary functions of religion is to help people develop sound social relationships. Third, a rapidly growing literature suggests that social support from fellow church members offsets the noxious effects of stress (Ellison et al. 2010), bolsters feelings of life satisfaction (Fiala, Bjorck, and Gorsuch 2002), and is associated with lower levels of anxiety, depression, and hostility (Willoughby et al. 2008). 
Figure 1

A conceptual model of gratitude to God, health, and depressive symptoms

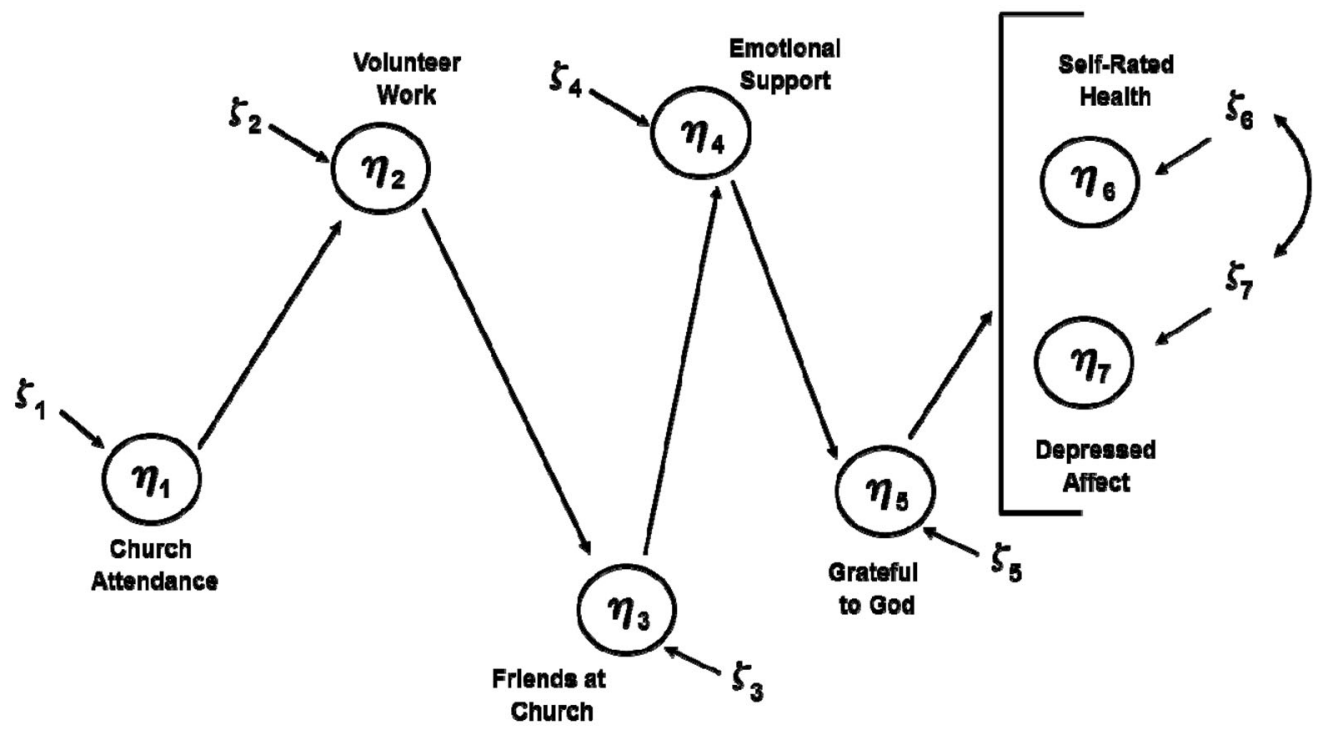

Gratitude to God, Health, and Depressive Symptoms

The conceptual model that we developed to examine the relationships among gratitude to God, health, and depressive symptoms is provided in Figure 1. Two steps were taken to simplify the presentation of this theoretical scheme. First, the elements of the measurement model (i.e., the factor loadings and measurement error terms) are not shown in this diagram even though a full measurement model was estimated when this conceptual scheme was evaluated empirically. Second, the model in Figure 1 was evaluated after the effects of age, sex, education, and marital status were controlled statistically (i.e., treated as exogenous variables).

It should be emphasized that all of the paths among all the variables in Figure 1 were estimated during the data analytic phase of this study (i.e., we estimated a fully saturated model). However, to keep the focus on the core theoretical processes we suspect are at work, paths are provided in Figure 1 for only the following core conceptual linkages: (1) people who go to church more often will be more likely to participate in volunteer work through their congregations; (2) individuals who perform volunteer work in the place where they worship will be more likely to become friends with their co-religionists; (3) people who have more friends where they worship will report receiving more emotional support from fellow congregants; (4) those who receive more support from co-religionists will feel more grateful to God; and (5) individuals who are more grateful to God will rate their health in a more favorable manner and experience fewer symptoms of depression.

\section{Church Attendance and Volunteer Work}

Although church-based social support may arise in a number of ways, we suspect that one source may be found in the interplay between church attendance and volunteer work. This specification is based on the following rationale. As Lundberg (2010) points out, all of the major faith traditions in the world extol the virtue of helping people who are in need. However, a key issue that arises at this juncture involves the way in which these fundamental precepts are transmitted to rank-and-file church members. One obvious venue involves participation in 
worship services. Basic religious principles are embedded in sermons, hymns, and group prayers that are often part of the typical worship service. And as Stark and Finke (2000) point out, people who attend worship services are more likely to adopt these religious teachings. Referring to religious precepts as "religious explanations," these investigators propose that "[c]onfidence in religious explanations increases to the extent that people participate in religious rituals" (Stark and Finke 2000:107).

So if one of the fundamental principles of religion is to help others, and religious principles are transmitted through attendance at worship services, then it follows that people who attend church more often should be more likely to participate in volunteer work programs that are available through their congregations.

\section{Church Attendance, Volunteer Work, and Friendship Ties}

According to our theoretical model, friendship ties in the church arise from two sources. The first has to do with church attendance. Although involvement in religion serves a number of functions (Hood, Hill, and Spilka 2009), there is considerable evidence that one of the most important functions has to do with the development and maintenance of close interpersonal relationships with fellow church members (Krause 2008). The widely cited research of Durkheim ([[1915]] 1965) shows that participation in religious rituals, such as worship services, helps build this type of interpersonal relationship.

The second potential source of friendship ties in church that is specified in our study model has to do with involvement in church-based volunteer work. Two theoretical perspectives help show volunteering in church may foster friendships with fellow church members.

Rook and Sorkin (2003) developed the first perspective. Their research suggests that older adults who participated in the Foster Grandparent Program report a significant increase in the number of new social relationships they were able to develop. The theoretical rationale they provide for these findings is especially useful for our purposes. Rook and Sorkin maintain that the goal-directed activities of volunteer work groups permit people to avoid "the inhibiting selfconsciousness and awkward expectations that often accompany interactions explicitly directed toward friendship formation" (2003:316). Instead, participating in the shared activities of a volunteer group makes it possible to subtly and discreetly assess a fellow participant's suitability as a friend because things like personal interests and beliefs can be expressed more naturally in conversations that arise in the process of engaging in shared group activities. In addition, Rook and Sorkin (2003) point out that the insider jokes and in-group stories that arise from common experiences in shared activities tend to bind individuals more tightly with other group members.

The second reason why volunteer work at church promotes close social ties is found in recent extensions of social identity theory. As Oyserman (2007) points out, greater involvement in a social group promotes stronger perceptions of similarity that, in turn, foster positive feelings about in-group members. As a result, the individual identifies more strongly with the group and is more likely to adopt the norms and values it espouses. Recently, Graham and Haidt (2010) extended this view by arguing that participation in common activities at church promotes a stronger sense of trust, cooperation, and loyalty. Cast within the context of this study, the fundamental precepts of social identity theory suggest that seeing greater similarity with fellow work group members, being more positively orientated to them, trusting them, and identifying with them should provide especially fertile ground for the development of strong informal relationships.

\section{Friendship Ties and Church-Based Emotional Support}

Unfortunately, the literature on friendships is in a state of disarray (Adams, Blieszner, and De Vries 2000). The terms "friendship" and "companionship" are used interchangeably, there is no agreed-upon definition of either term, and researchers have not reached a consensus on 
the key characteristics and functions of companion friends. It is not possible to resolve these longstanding problems in this study. Instead, we make an effort to contribute to the ongoing development of research in this field by focusing on several core characteristics of companion friends that cut across the discussions that have appeared so far (Ueno and Adams 2006). Four interrelated functions of companion friends are examined briefly below.

First, companion friends are characterized by a high degree of self-disclosure (Patterson, Bettini, and Nussbaum 1993). This means, for example, that close companion friends tell each other things they would not usually share with other people (Rook 1987). Clearly, this kind of intimate self-disclosure cannot take place without a high degree of openness, honesty, and truthfulness.

Second, as Cocking and Kennett (1998) argue, companion friends share things they value highly. For example, they share plans, hopes, dreams, ambitions, and interests. And if friendships form in volunteer work groups at church, it is likely they share values associated with helping others. Writing over a century ago, Ross illuminated how the shared values and experiences that arise in religious settings foster friendships that are especially close. He argued that "[t]o have the same gods, to be watched, loved, and protected by the same deities, to be destined to join the same unforeseen company at death ... these created fellowship" (Ross 1896:437). In fact, Ross went on to argue that friendships that form at church are so close that they become like family ties: "conviction of our fundamental identity in nature and destiny ... [is] the modern counterpart of the old blood bond" (1896:441).

Third, companion friends strive to emulate what they admire in their counterpart. As Sherman argues, "[e]ach is inspired to develop himself more completely as he sees admirable qualities, not fully realized in himself, manifest in another whom he esteems .... Character friends, as extended yet different selves, are eminently suited as models to be emulated" (1993:105-06).

The final characteristic of companion friends is related to the previous one. It has to do with the way in which self-development and personal growth arises from emulating a close companion friend. Instead of merely being an aloof role model, companion friends actively encourage and spur the other on to greater self-awareness and greater personal growth. Simply put, companion friends invest time and effort to help each other attain that which they value in each other.

If church-based friendships are characterized by a high level of self-disclosure, admiration, and shared values, and if close friends bring out the best in each other, then it is not difficult to see why we hypothesize that friendship ties that form in a congregation should be an especially important source of emotional support.

\section{Church-Based Emotional Support and Gratitude to God}

Lundberg (2010) reports that all the major faith traditions in the world emphasize the importance of loving others, helping people who are in need, and forgiving individuals for the transgressions they have committed. As a result, social relationships in the church may be especially beneficial. In fact, this is one reason why research by Krause (2006b) suggests that social relationships that are formed in the church may have a more beneficial effect on health than social relationships that are formed outside the church. Finding especially beneficial relationships in the church is important because the vast literature on negative interaction (Rook 1984) suggests that relationships may often become conflicted and troublesome. So if religious principles forge close relationships in the church and people benefit from these relationships by receiving more emotional support from their fellow church members, then it follows they should feel especially grateful to God.

\section{Gratitude to God and Health}

As shown in Figure 1, we evaluate the relationship between gratitude to God and self-rated health as well as the relationship between gratitude to God and depressive symptoms. There are 
two reasons for following this strategy. First, as we discussed earlier, there is some evidence that feelings of gratitude to God are associated with both outcomes. By assessing the relationship between the two outcomes simultaneously, we will be able to see if the relationship between gratitude toward God and health is stronger, the same, or weaker than the relationship between gratitude to God and depressive symptoms. Second, researchers have known for some time that when people are asked to rate their own physical health status they often take their own mental health into account (Idler, Hudson, and Leventhal 1999). So to make sure that self-rated health reflects physical health per se and not mental health, it is important to include both outcomes in the same model.

There are three reasons why feelings of gratitude to God may affect physical and mental health. First, as Emmons (2004) points out, gratitude is a positive emotion that arises from the pleasant feelings that are associated with receiving a benefit. Viewing gratitude as a positive emotion is important because a rapidly growing body of research indicates that positive emotions are associated with a range of beneficial physiological effects, including a lower heart rate, lower blood pressure, and improved immune functioning (Rozanski and Kubzansky 2005; DuBois et al. 2012). Second, research reviewed by DuBois and her associates reveals that positive emotions, such as gratitude, are associated with the adoption of a range of beneficial health behaviors, including exercise and medication compliance (DuBois et al. 2012). Third, research by Krause (2006a) indicates that people who feel more grateful to God are able to cope more effectively with the deleterious effects of stress.

\section{Methods}

\section{Sample}

Recall that the data for this study come from the U.S. Congregational Life Survey, which involves a complex sampling design. Altogether, two waves of interviews have been collected. The data for this study came from a subsample of participants in the Wave 2 (2008/2009) interviews, which include some of the original Wave 1 study participants as well as people who had not participated in the study up to that point. To identify the participants in this study more clearly, we first describe the Wave 1 sampling strategy. Then we discuss the Wave 2 sampling procedures, followed by a brief explanation of how the subsample of Wave 2 participants was selected.

The study participants in Wave 1 were identified through a hyper-network sampling strategy. This sampling strategy was executed in four steps. First, a random sample was drawn of adults in the United States who indicated they attended a worship service at least once in the previous year. Second, these individuals were asked to identify the name of the place where they worship. Third, the congregations that were identified through this process were invited to participate in the study. Because the individuals who identified the congregations were sampled at random, it is safe to assume that the congregations they named comprise a random sample of all congregations in the United States. Fourth, self-administered questionnaires were distributed to the people who attended worship services in the named congregations during April 2001. The phrase "hypernetwork sampling" is therefore used to denote that the sample contains individuals who are linked by common membership in a given congregation (see McPherson 1982 for a detailed discussion of this sampling strategy).

The Wave 2 survey was conducted in 2008. The Wave 2 sample is comprised of two groups. The first group consisted of the 1,214 congregations that participated at Wave 1. Of this group, 411 agreed to participate at Wave 2 (33.9 percent). A total of 36,468 completed surveys were obtained from the first group. It is important to emphasize that the data at the individual level are not longitudinal because even though the same congregations may have participated in the 
Wave 1 and Wave 2 surveys, there is no guarantee that the same individuals filled out a questionnaire both times.

The second group was comprised of individuals who did not come from congregations that participated at Wave 1. These individuals were identified through the hyper-network sampling strategy described above. A total of 1,330 congregations were identified for the second group and 148 returned completed questionnaires (11.1 percent). A total of 26,206 completed surveys were obtained from the second group.

A self-administered questionnaire consisting of core items was given to all Wave 2 study participants. However, in an effort to maximize the amount of information that could be obtained at Wave 2, a series of supplementary questionnaires were distributed at random to subsets of worshipers in participating congregations. The questions on health, depressive symptoms, emotional support, and gratitude to God were administered to one or more worshipers randomly in each participating congregation.

The full information maximum likelihood estimation (FIML) procedure was used to deal with item nonresponse in the data. Simulation studies suggest that the FIML procedure is preferable to list-wise deletion because list-wise deletion may produce biased estimates (Enders 2010). Moreover, as Enders (2010) points out, FIML is equivalent to more time-consuming procedures for dealing with item nonresponse, such as multiple imputation. Preliminary analysis suggests that the amount of item nonresponse ranged from 14 percent for the measures of depressive symptoms to no missing data for the measure of performing volunteer work in the church. Complete data were available from 833 study participants after the FIML procedure was implemented.

Preliminary analysis of the data provided by the 833 study participants revealed that their average age was 54.7 years $(S D=18.1$ years), 38.8 percent were men, and 67.2 percent were married at the time of the survey. The level of educational attainment in this study was coded into an eight-category ordinal scheme. The mean value for this measure was $5.7(S D=1.7)$, which roughly corresponds to individuals with a completed high school education.

\section{Measures}

The indicators that were used to assess the constructs in the study model are provided in Table 1. The procedures that were used to code these variables may be found in the footnotes of this table.

\section{Church Attendance}

A single item was used to assess how often study participants attend worship services. A high score denotes more frequent church attendance. The mean on this ordinal measure is 5.63 $(S D=1.23)$.

\section{Volunteer Work at Church}

A binary measure was created that reflects whether study participants regularly participate in community service, social justice, or advocacy activities through their congregations. A high score identifies those who participate in this type of volunteer work. The data indicate that 23.1 percent of the individuals in this study participate in volunteer work at church.

\section{Close Friends at Church}

A single indicator was also used to see if study participants had close friends in their congregations. This four-category ordinal measure ranges from having no close friends at church 
Table 1: Core study measures

1. Church attendance ${ }^{\mathrm{a}}$

How often do you go to worship services at this congregation?

2. Volunteer work ${ }^{\mathrm{b}}$

Do you currently take part in any activities of this congregation that reach out to the wider community? Yes, in community service, social justice, or advocacy for this congregation.

3. Friends at church $^{\mathrm{c}}$

Do you have any close friends in this congregation?

4. Emotional support from church members ${ }^{\mathrm{d}}$

A. Please think about the people in your congregation other than you minister, pastor, priest, or rabbi. Over the past year, how often have people in this congregation let you know they love and care for you?

B. How often have people in this congregation talked with you about your private problems and concerns?

C. How often have the people in this congregation expressed interest and concern in your well-being?

5. Gratitude to Gode

A. I am grateful for all God has done for me.

B. If I were to make a list of all the things that God has done for me, it would be a very long list.

C. As I look back on my life, I feel I have been richly blessed by God.

6. Self-rated health ${ }^{\mathrm{f}}$

How would you rate your overall health at the present time?

7. Depressive symptoms ${ }^{\mathrm{g}}$

A. I could not shake off the blues, even with the help of family and friends.

B. I felt depressed.

C. I had crying spells.

D. I felt sad.

\footnotetext{
${ }^{\text {a }}$ This item is scored in the following manner (coding in parentheses): this is my first time (1); hardly ever or special occasions only (2); less than once a month (3); once a month (4); two or three times a month (5); usually every week (6); more than once a week (7).

${ }^{\mathrm{b}}$ This item is scored in the following manner: not involved in volunteer work at church (0); involved at volunteer work at church (1).

${ }^{\mathrm{c}}$ This item is scored in the following manner: I have little contact with others from this congregation outside of activities here (1); I have some friends in this congregation but my closest friends are not involved here (2); I have some close friends here as well as other close friends that are not part of this congregation (3); Most of my closest friends are part of this congregation.

${ }^{\mathrm{d}}$ These items are scored in the following manner: never (1); once in a while (2); fairly often (3); very often (4).

${ }^{\mathrm{e}}$ These items are scored in the following manner: disagree strongly (1); disagree somewhat (2); agree somewhat (3); agree strongly (4).

${ }^{f}$ This item is scored in the following manner: poor (1); fair (2), good (3); excellent (4).

${ }^{\mathrm{g}}$ This items are scored in the following manner: rarely/none (1); some/a little (2); moderate amount (3); often/always (4).
}

to having most of one's closest friends at church. A high score stands for those who have more close friends in the place where they worship. The mean is $2.65(S D=.86)$.

\section{Emotional Support from Church Members}

Three indicators that were devised by Krause (2008) were used to measure how often the participants in this study receive emotional support from their fellow church members. A high score represents those who receive emotional support more often. The mean is $7.68(S D=2.72)$. 


\section{Gratitude to God}

As shown in Table 1, three indicators were used to assess feelings of gratitude to God. The first two indicators come from the work of McCullough, Tsang, and Emmons (2002). The third item was taken from Peterson and Seligman's (2004) measure of gratitude. A high score denotes stronger feelings of gratitude to God $(M=11.49 ; S D=1.11)$.

\section{Self-Rated Health}

Self-rated health was assessed with three widely used measures. A high score on these items stands for more favorable health ratings. The mean is $3.22(S D=.69)$.

\section{Depressive Symptoms}

Depressive symptoms were assessed with four indicators from the Center for Epidemiologic Study Depression Scale (Radloff 1977). We deliberately selected indicators that capture a depressed affect. This scale also contains items that assess the somatic symptoms of depression (e.g., difficulty sleeping and eating), but research by Wells and Strickland (1982) suggests that without additional information it is not possible to tell if somatic symptoms reflect "true" physical health problems or symptoms associated with depression. Because one of our goals is to compare and contrast the effects of gratitude to God on physical and mental health problems, we wanted to select indicators of depression that do not confound the two. A high score on the depressed affect items stands for more mental health problems $(M=6.34 ; S D=2.37)$.

\section{Results}

The findings from this study are presented below in three sections. Issues involving the estimation of the study model are discussed in the first section. Data on the reliability of the multiple-item constructs is presented in the second section. The third section contains the substantive findings that were derived from estimating our conceptual scheme.

\section{Model Estimation Issues}

The model depicted in Figure 1 was evaluated with the maximum likelihood estimator in Version 8.80 of the LISREL statistical software program (du Toit and du Toit 2001). Use of this estimator is based on the assumption that the observed indicators have a multivariate normal distribution. Preliminary tests (not shown here) revealed that this assumption had been violated in this study. Although there are a number of ways to deal with departures from multivariate normality, the straightforward approach that is discussed by du Toit and du Toit (2001) was followed here. These investigators report that departures from multivariate normality can be handled by converting raw scores of the observed indicators to normal scores before estimating the model (du Toit and du Toit 2001:143). Based on these insights, the analyses presented below were performed with observed indicators that were normalized. The formula we use to normalize the observed indicators was developed by Joreskog and Sorbom (1986:1-6). This formula produces values that are akin to $z$-scores. More specifically, the transformed variables have a mean of zero and a standard deviation that is typically very close to one.

Because the FIML procedure was used to deal with item nonresponse, the LISREL software program provides only two goodness-of-fit measures. The first is the FIML chi-square (221.721 with 88 degrees of freedom, $p<.000$ ). Unfortunately, this statistic substantially underestimates the fit of the model to the data when samples are large, such as the sample in this study. A better grasp of the fit of the model to the data is provided by the second goodness-of-fit measure-the root mean square error of approximation (RMSEA). The RMSEA value for the model in Figure 1 
Table 2: Measurement error parameter estimates for multiple item study measures

\begin{tabular}{lcc}
\hline & Factor Loading $^{\mathrm{a}}$ & Measurement $^{\text {Error }^{\mathrm{b}}}$ \\
\hline 1. Emotional support from church members & & .286 \\
A. Love and care for you & $\mathrm{c}$ & .350 \\
B. Your private problems and concerns & .806 & .179 \\
C. Interest and concern in your well-being & .906 & \\
2. Gratitude to God & & .327 \\
A. Grateful for all God has done & .821 & .307 \\
B. List all the things God has done & .833 & .263 \\
C. Richly blessed by God & .858 & .491 \\
3. Depressive symptoms & & .297 \\
A. Could not shake off the blues & .713 & .613 \\
B. I felt depressed & .838 & .433 \\
C. I had crying spells & .622 & .753 \\
D. I felt sad & & \\
\hline
\end{tabular}

Note: $N=833$.

${ }^{a}$ Factor loadings are from the completely standardized solution. The first-listed item for each latent construct was fixed at 1.0 in the unstandardized solution.

${ }^{\mathrm{b}}$ Measurement error terms are from the completely standardized solution. All factor loadings and measurement error terms are significant at the .001 level.

${ }^{\mathrm{c}}$ Item content is paraphrased for the purpose of identification. See Table 1 for the complete text of each indicator.

is .043. As Kelloway (1998) suggests, values below .05 indicate a very good fit of the model to the data. ${ }^{1}$

\section{Reliability of the Observed Indicators}

Table 2 contains the factor loadings and measurement error terms that were derived from estimating the study model. These coefficients are important because they provide preliminary information about the reliability of the multiple-item study measures. Kline (2011) notes that standardized factor loadings in excess of .600 suggest that items have reasonably good reliability. As the data in Table 3 indicate, the standardized factor loadings range from .622 to .906 , indicating that the measures that are used in this study have an acceptable level of reliability.

Although the factor loadings and measurement error terms that are associated with the observed indicators provide useful information about the reliability of each item, it would be helpful to know something about the reliability for the scales as a whole. It is possible to compute these reliability estimates with a formula provided by DeShon (1998). This procedure is based on the factor loadings and measurement error terms in Table 2. Applying the procedures described by DeShon (1998) to these data yields the following reliability estimates for the multiple-item constructs in Figure 1: emotional support from fellow church members (.889); gratitude to God (.876); and depressive symptoms (.824). Taken as a whole, the data provided in this section suggest that the reliability of the multiple-item study measures is good.

\footnotetext{
${ }^{1}$ An alternative model was run that contains only the core hypotheses that were identified when the model was introduced. The fit of this alternative model to the data is: chi-square $=332.247$; degrees of freedom $=102$; RMSEA $=.052$. The difference in chi-square values between the fully saturated model and the alternative model is 110.526 with 14 degrees of freedom. The difference in fit between the two models is significant at the .001 level. Viewed in a more substantive way, this means that the fit of the alternative model deteriorated significantly from the fully saturated model.
} 


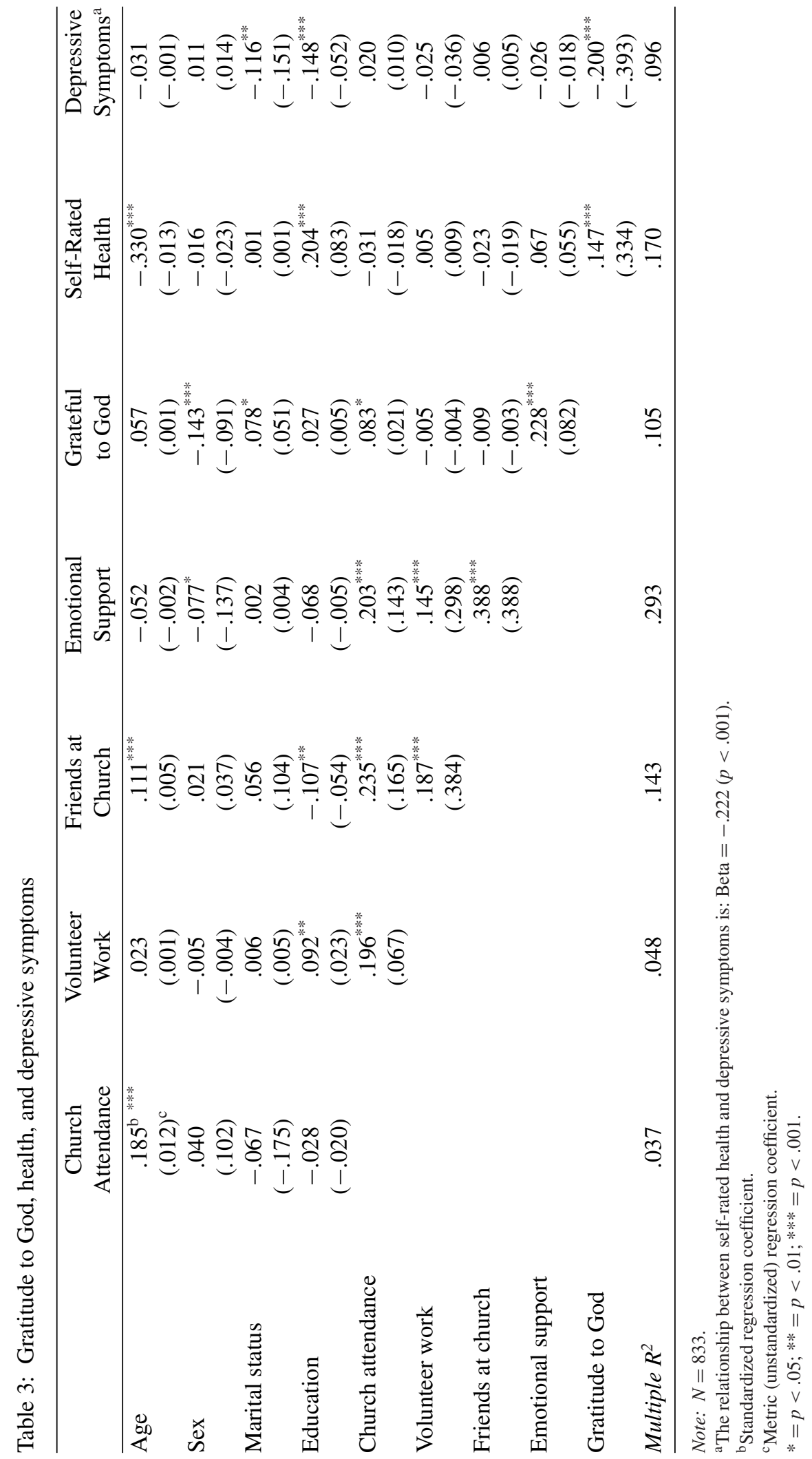




\section{Substantive Findings}

The substantive findings that were derived from estimating the study model are provided in Table 3. Taken as a whole, these data provide support for the hypotheses that were developed earlier. More specifically, the results indicate that people who attend worship services more often are more likely to perform volunteer work in their congregations (Beta $=.196 ; p<.001$ ). This is important because the findings further reveal that individuals who participate in church volunteer programs are likely to say they have more close friends in their congregations (Beta $=.187 ; p<$ .001). The data further reveal that, as hypothesized, more frequent church attendance is associated with having more friends at church, as well (Beta $=.235 ; p<.001)$. The fact that a significant relationship between volunteering and friendships at church is present after the effects of church attendance were taken into account is consistent with the notion that engaging in volunteer work may perform a unique role in friendship formation.

Returning to Table 3, the data suggest that people who have more friends in their congregations report they receive more emotional support from their fellow church members $($ Beta $=.388$; $p<.001)$. The study findings reveal that receiving emotional support from significant others at church represents one reason why people feel more grateful to God (Beta $=.228 ; p<.001)$. Consistent with earlier research, the results indicate that individuals who feel more grateful to God are more likely to rate their health in a favorable manner (Beta $=.147 ; p<.001)$ and they are less likely to experience symptoms of depression (Beta $=-.200 ; p<.001){ }^{2}$

Recall that we included both health and depressive symptoms in the model so that we could see if feeling grateful to God is more strongly associated with one than the other. The findings in Table 3 appear to indicate that feelings of gratitude to God are more strongly associated with depressive symptoms, but it is possible to conduct a formal test to see if the difference between these estimates is statistically significant. This test is performed in two steps. First, the findings in Table 3 were derived after the relationships among gratitude, health, and depressive symptoms were permitted to vary freely. This produced the chi-square goodness-of-fit estimate that was reported above. Following this, a second pass was made through the data after the size of the relationship between gratitude to God and health was constrained to equal the size of the relationship between gratitude to God and depressive symptoms. This produced a second chi-square goodness-of-fit value. The difference between the two chi-square values (with 1 degree of freedom) can be used to see if the unstandardized estimate of the relationship between gratitude and health differs significantly from the unstandardized estimate of the relationship between gratitude and depressive symptoms. The findings from this additional test suggest that the relationship between gratitude to God and depressive symptoms is significantly larger than the corresponding estimate for health $(p<.001)$.

One additional finding in Table 3 should be addressed because it adds depth to our understanding of the process we are trying to capture. The data indicate that compared to individuals who attend worship services less frequently, people who attend church more often appear to be only slightly more grateful to God (Beta $=.083 ; p<.05)$. Taken at face value, the magnitude of this relationship seems somewhat surprising because worship services are typically a major venue for expressing feelings of gratitude to God. Fortunately, turning to an additional set of analyses provides greater insight into this issue.

One advantage of working with latent variable models arises from the fact that it is possible to explicitly estimate the indirect and total effects that operate through a model. This means, for example, that people who go to church more often receive more emotional support from fellow

\footnotetext{
${ }^{2}$ An ordinary least squares regression analysis was run to see if there is a statistically significant interaction effect in the data between the frequency of church attendance and volunteering on having friends in church. The findings suggest that this interaction was not statistically significant $(p=.527)$.
} 
church members and more emotional support, in turn, bolsters feelings of gratitude to God. Further analysis reveals that when all the indirect pathways in the model that connect church attendance with gratitude are taken into account (Beta $=.074 ; p<.001$; not shown in Table 3 ), the resulting total effect of church attendance on gratitude to God is noticeably larger (total effect $=.083+.074=.157 ; p<.001$; not shown in Table 3 ). Cast in more substantive terms, this means that a significant part of the reason why people who go to church feel grateful to God may be traced to the volunteer work they perform at church, the friendship ties this fosters, and the emotional support these church-based friends provide (i.e., $.074 / .157=47.1$ percent).

\section{DisCUSSION}

Robert Roberts is a contemporary ethicist who succinctly captured the social basis of religion: "The church is a society of people who have undertaken the struggle to love one another with a spiritual love. We teach one another week in and week out.... We cultivate ourselves and one another in the consciousness of a calling to perfect fellowship" (Roberts 2007:91). But as Krause (2008) points out, close relationships with religious others are manifest in a number of ways. The purpose of the present study was to explore one way in which these social ties may arise. In the process, we also focused on whether these social relationships are, in turn, associated with greater feelings of gratitude to God. Moreover, we made an effort to see if feelings of gratitude to God are associated with health and depressive symptoms.

Support was found in our latent variable model for the following relationships. Data from Wave 2 of the U.S. Congregational Life Survey indicate more frequent church attendance is associated with a greater likelihood of participating in church-sponsored volunteer work. This finding is consistent with research reviewed by Musick and Wilson (2008). Our data further suggest that both church attendance and volunteer work are, in turn, associated with having more friends at church. The fact that church attendance may be associated with close social ties is consistent with Collins's (2004) theory of interaction ritual chains. The findings from this study go on to suggest that people with more close friends in the place they worship are likely to report receiving more emotional support from them. And consistent with prior studies (Krause and Ellison 2009), the findings from this study indicate that individuals who get more emotional support from fellow church members appear to be more grateful to God. Finally, as other studies have shown (Krause 2006a), feeling more grateful to God is associated with more favorable self-rated health and fewer symptoms of depression. And of the two, feeling grateful to God is appears to be associated more strongly with depressive symptoms than self-rated health.

Although our study may have contributed to the literature, a considerable amount of work remains to be done. Three areas are in need of further research. First, when our conceptual model was introduced, we briefly identified a number of characteristics of close companion friendships. We noted, for example, that close companion friends help each other to grow personally and there is a good deal of self-disclosure in these relationships. However, these attributes were not evaluated empirically in this study. Krause and Cairney (2009) provide some evidence that these friendship characteristics are important, but their research was based on data that were provided by older people. More work is needed to see if friendships that are formed by younger adults operate in a similar manner. Second, this study focused solely on support that is received from fellow church members and feelings of gratitude to God. However, research also reveals that in addition to receiving support from others, people also provide support to significant others (Krause 2008). Because helping others is valued highly by all faith traditions (Lundberg 2010), getting the chance to assist others may bolster feelings of gratitude toward God, as well. More research is needed to empirically evaluate this possibility. Third, our research shows that engaging in volunteer work at church may promote friendships with fellow church members. However, 
people also perform volunteer work outside religious settings. Consequently, it is important to know if volunteering in a secular organization fosters close friendships, as well.

In the process of addressing these issues researchers should also take steps to deal with the limitations in our work. One limitation is important. The data for this study were gathered at a single point in time only. Consequently, the causal ordering among the constructs in our conceptual model was based on theoretical considerations alone. Some researchers may therefore legitimately propose other causal orderings. For example, we argued that people who feel grateful to God subsequently enjoy better health. However, one could just as easily maintain that people who have good health are subsequently more grateful to God. Clearly, this relationship, as well as other causal assumptions that are embedded in our study model, should be evaluated more rigorously with data that have been gathered at more than one point in time.

Although there are limitations in the work we have done, we hope our study findings encourage other investigators to join in research on church-based social relationships, feelings of gratitude toward God, and health.

\section{REFERENCES}

Adams, Rebecca G., Rosemary Blieszner, and Brian De Vries. 2000. Definitions of friendship in the third age: Age, gender, and study location effects. Journal of Aging Studies 14(1):117-33.

Algoe, Sara B., Jonathan Haidt, and Shelly L. Gable. 2008. Beyond reciprocity: Gratitude and relationships in everyday life. Emotion 8(3):425-29.

Baldwin, J. M. 1902. Fragments in philosophy and science of being: Collected essays and addresses. New York: Charles Scribner's Sons.

Barna, George. 2006. The state of the church: 2006. Ventura, CA: Barna Group, Ltd.

Carlisle, Robert D. and Jo-Ann Tsang. 2013. The virtues: Gratitude and forgiveness. In APA handbook of psychology, religion, and spirituality, vol. 1, edited by Kenneth Pargament, Julie J. Exline, and James W. Jones, pp. 423-27. Washington, DC: American Psychological Association.

Cocking, Dean and Jeanette Kennett. 1998. Friendship and the self. Ethics 108(3):502-27.

Collins, Randall. 2004. Interaction chain rituals. Princeton, NJ: Princeton University Press.

DeShon, Richard P. 1998. A cautionary note on measurement error correlations in structural equation models. Psychological Methods 3(3):412-23.

DuBois, Christina M., Scott R. Beach, Todd B. Kasdan, Maren B. Nyer, Elyse R. Park, Christopher M. Celano, and Jeff C. Huffman. 2012. Positive psychological attributes and cardiac outcomes: Associations, mechanisms, and interventions. Psychosomatics 53(4):303-18.

Durkheim, Emile. [1915]/1965. Elementary forms of religious life. London: Allen Unwin, Ltd.

du Toit, Mathilda and Stephen du Toit. 2001. Interactive LISREL: User's guide. Lincolnwood, IL: Scientific Software International.

Ellison, Christopher G., Lori A. Roalson, Janelle M. Guillory, Kevin J. Flannelly, and John P. Marcum. 2010. Religious resources, spiritual struggles, and mental health in a nationwide sample of PCUSA clergy. Pastoral Psychology 59(3):287-304.

Emmons, Robert A. 2004. The psychology of gratitude: An introduction. In The psychology of gratitude, edited by Robert A. Emmons and Michael E. McCullough, pp. 3-16. New York: Oxford University Press.

Emmons, Robert A. and Michael E. McCullough. 2003. Counting blessings versus burdens: An experimental investigation of gratitude and subjective well-being in daily life. Journal of Personality and Social Psychology 84(2):377-89.

Enders, Craig C. 2010. Applied missing data analysis. New York: Guilford.

Fiala, William E., Jeffrey B. Pjorck, and Richard Gorsuch. 2002. The religious support scale: Construction, validation, and cross-validation. American Journal of Community Psychology 30(6):761-86.

Froh, Jeffrey J., Todd B. Kashdan, Kathleen M. Ozimkowski, and Norman Miller. 2009. Who benefits the most from a gratitude intervention in children and adolescents? Examining positive affect as a moderator. Journal of Positive Psychology 4(5):408-22.

Galen, Luke W. 2012. Does religious belief promote prosociality? A critical examination. Psychological Bulletin 138(5):876-906.

Graham, Jesse and Jonathan Haidt. 2010. Beyond beliefs: Religions bind individuals to moral communities. Personality and Social Psychology Review 14(1):140-50.

Harpham, Edward J. 2004. Gratitude in the history of ideas. In The psychology of gratitude, edited by Robert A. Emmons and Michael E. McCullough, pp. 19-36. New York: Oxford University Press.

Hood, Ralph W., Peter C. Hill, and Bernard Spilka. 2009. The psychology of religion, 4th ed. New York: Guilford. 
Idler, Ellen L., Shawna V. Hudson, and Howard Leventhal. 1999. The meanings of self-rated health: A qualitative and quantitative inquiry. Research on Aging 21(3):458-76.

Joreskog, Karl G. and Dag Sorbom. 1986. PRELIS: A program for multivariate data screening and data summarization. Mooresville, IN: Scientific Software.

Kelloway, E. Kevin. 1998. Using LISREL for structural equation modeling. Thousand Oaks, CA: Sage.

Kline, Rex. 2011. Principles and practice of structural equation modeling, 3rd ed. New York: Guilford.

Komter, Aafke Elisabeth. 2004. Gratitude and gift exchange. In The psychology of gratitude, edited by Robert A. Emmons and Michael E. McCullough, pp. 195-212. New York: Oxford University Press.

Krause, Neal. 2006a. Gratitude toward God, stress, and health in late life. Research on Aging 28(2):163-83.

- 2006b. Exploring the stress-buffering effects of church-based social support and secular social support on health in late life. Journal of Gerontology: Social Sciences 61B(1):S35-S43.

- 2008. Aging in the church: How social relationships affect health. West Conshohocken, PA: Templeton Foundation Press.

Krause, Neal and John Cairney. 2009. Close companion friends in church and health in late life. Review of Religious Research 51(1):181-200.

Krause, Neal and Christopher G. Ellison. 2009. The social environment of the church and feelings of gratitude toward God. Psychology of Religion and Spirituality 1(3):191-205.

Krause, Neal, Lindsay A. Evans, Gregory Powers, and R. David Hayward. 2012. Feeling grateful to God: A qualitative inquiry. Journal of Positive Psychology 7(2):119-30.

Lundberg, C. David. 2010. Unifying truths of the world's religions. New Fairfield, CT: Heavenlight Press.

McCullough, Michael E., JoAnn Tsang, and Robert A. Emmons. 2002. The grateful disposition: A conceptual and empirical topography. Journal of Personality and Social Psychology 82(1):112-27.

McPherson, J. Miller. 1982. Hypernetwork sampling: Duality and differentiation among voluntary organizations. Social Networks 3(2):225-49.

Musick, Marc A. and John Wilson. 2008. Volunteers: A social profile. Bloomington: Indiana University Press.

Oyserman, Daphna. 2007. Social identity and self-regulation. In Social psychology: Handbook of basic principles, edited by Arie W. Kruglanski and E. Tory Higgins, pp. 432-53. New York: Guilford.

Patterson, Brian R., Lorraine M. Bettini, and Jon F. Nussbaum. 1993. The meaning of friendship across the life span: Two studies. Communication Quarterly 41(2):145-60.

Peterson, Christopher and Martin E. P. Seligman. 2004. Character strengths and virtues: A handbook and classification. New York: Oxford University Press.

Radloff, Lenore S. 1977. The CES-D Scale: A self-report depression scale for research in the general population. Applied Psychological Measurement 1(3):385-401.

Roberts, Robert C. 2007. Spiritual emotions: A psychology of Christian virtues. Grand Rapids, MI: Eerdmans.

Rook, Karen S. 1984. The negative side of social interaction: Impact on psychological well-being. Journal of Personality and Social Psychology 46(5):1097-1108.

- 1987. Social support versus companionship: Effects of life stress, loneliness, and evaluations of others. Journal of Personality and Social Psychology 52(6):1132-47.

Rook, Karen S. and Danya H. Sorkin. 2003. Fostering social ties through a volunteer role: Implications for older adults' psychological health. International Journal of Aging and Human Development 57(4):313-37.

Rosmarin, David H., Steven Pirutinsky, Adam B. Cohen, Yardana Galler, and Elizabeth J. Krumrei. 2011. Grateful to God or just plain grateful? A comparison of religious and general gratitude. Journal of Positive Psychology 6(5):389-96.

Ross, Edward Alworth. 1896. Social control V. American Sociological Review 2(5):433-45.

Rozanski, Alan and Laura D. Kubsansky. 2005. Psychologic functioning and physical health: A paradigm of flexibility. Psychosomatic Medicine 67(Suppl 1):S47-S53.

Sherman, Nancy. 1993. Aristotle and the shared life. In Friendship: A philosophical reader, edited by Neera K. Badhwar, pp. 91-107. Ithaca, NY: Cornell University Press.

Stark, Rodney and Roger Finke. 2000. Acts of faith: Explaining the human side of religion. Berkeley: University of California Press.

Tsang, Jo-Ann. 2007. Gratitude for small and large favors: A behavioral test. Journal of Positive Psychology 2(3):157-67.

Ueno, Koji and Rebecca G. Adams. 2006. Adult friendship: A decade review. In Close relationships: Functions, forms, and processes, edited by Patricia Noller and Judith A. Feeney, pp. 151-169. New York: Taylor \& Francis.

Wells, James A. and Donald E. Strickland. 1982. Physiogenic bias as invalidity in psychiatric symptom scales. Journal of Health and Social Behavior 23(3):235-52.

Willoughby, Michael T., R. Jean Cadigan, Margaret Burchinal, and Debra Skinner. 2008. An evaluation of the psychometric properties and criterion validity of the religious social support scales. Journal for the Scientific Study of Religion 47(1):147-59.

Wood, Alex M., Jeffrey J. Froh, and Adam W. Geraghty. 2010. Gratitude and well-being: A review and theoretical integration. Clinical Psychology Review 30(7):890-905. 